\title{
Hierarchical Control of Drosophila Sleep, Courtship, and Feeding Behaviors by Male-Specific P1 Neurons
}

\author{
Wenxuan Zhang ${ }^{1}$ Chao Guo ${ }^{1} \cdot$ Dandan Chen $^{1} \cdot$ Qionglin Peng ${ }^{1} \cdot$ Yufeng Pan ${ }^{1,2}$
}

Received: 27 February 2018/Accepted: 3 May 2018/Published online: 4 September 2018

(C) The Author(s) 2018

\begin{abstract}
Animals choose among sleep, courtship, and feeding behaviors based on the integration of both external sensory cues and internal states; such choices are essential for survival and reproduction. These competing behaviors are closely related and controlled by distinct neural circuits, but whether they are also regulated by shared neural nodes is unclear. Here, we investigated how a set of male-specific P1 neurons controls sleep, courtship, and feeding behaviors in Drosophila males. We found that mild activation of P1 neurons was sufficient to affect sleep, but not courtship or feeding, while stronger activation of P1 neurons labeled by four out of five independent drivers induced courtship, but only the driver that targeted the largest number of P1 neurons affected feeding. These results reveal a common neural node that affects sleep, courtship, and feeding in a threshold-dependent manner, and provide insights into how competing behaviors can be regulated by a shared neural node.
\end{abstract}

Keywords Drosophila · Courtship · Sleep · Feeding · P1 neurons $\cdot$ Neural circuit

Electronic supplementary material The online version of this article (https://doi.org/10.1007/s12264-018-0281-z) contains supplementary material, which is available to authorized users.

Yufeng Pan

pany@seu.edu.cn

1 The Key Laboratory of Developmental Genes and Human Disease, Institute of Life Sciences, Southeast University, Nanjing 210096, China

2 Co-innovation Center of Neuroregeneration, Nantong University, Nantong 226019, China

\section{Introduction}

A fundamental question in biology is how animals sense environmental cues and alter their physiology and behavior in ways that are beneficial for their survival and reproduction. The amenability of Drosophila melanogaster as a model system using genetic and physiological approaches makes it ideal for exploring the neural mechanisms underlying a variety of behaviors including sleep, courtship, and feeding. Indeed, substantial progress has been made on how these individual behaviors are controlled by specific neuronal circuits, often referred to as sleep circuits, courtship circuits, and feeding circuits [1-6].

Sleep, courtship, and feeding behaviors are mutually exclusive in principle. Very little is known about how these behaviors cross-talk at the level of neuronal circuits. Recently, we showed that sleep and sexual behaviors interact in a sex-specific way and identified sexually dimorphic neurons that mediate the interplay between sleep and sex [7]. Among these neurons, P1 neurons are of particular interest because they serve as a higher center that integrates both external sensory cues and social experience [8-12]. It has also been found that P1 neurons regulate male aggression, as a P1-activated male fly is more aggressive if presented with another male [13]. P1 neurons are only present in males and express the male-specific Fruitless (FruM) and Doublesex (DsxM) proteins [11, 14-16], which are crucial for male sexual development and behaviors [17-20]. It is generally accepted that the activity of P1 neurons is positively correlated with male sexual arousal in flies [8, 10, 15]. However, it is still unclear whether P1 neurons represent a general arousal state and modulate many other behaviors, and if so, how multiple behaviors are controlled by the same set of neurons. 
Here, we used five independent driver lines that labeled P1 neurons ranging from 9 to 23 cells per hemisphere (20\%-50\% of all P1 neurons) to determine how P1 activation affects sleep, courtship, and feeding behaviors in Drosophila.

\section{Materials and Methods}

\section{Fly Stocks}

Flies were maintained at $22^{\circ} \mathrm{C}$ under a $12 \mathrm{~h}: 12 \mathrm{~h}$ light:dark cycle. Split-GAL4 reagents including R15A01-AD, R17D06-AD, R71G01-DBD, and R22D03-DBD, as well as R17D06-LexA and R71G01-LexA have been described previously [21, 22] and were obtained from Janelia Research Campus (Ashburn, VA). $d s x^{G A L A}, U A S>$ stop $>d T r p A 1, U A S>$ stop $>$ myrGFP, and LexAop2-FlpL were used as previously described $[15,23]$.

\section{Sleep Test and Analysis}

Individual 2-4 day-old male flies were placed in locomotor activity monitor tubes (DAM2, TriKinetics Inc., Waltham, MA) with fly food ( $2 \%$ agarose and 5\% sugar), and entrained under $22^{\circ} \mathrm{C}$ and $12 \mathrm{~h}: 12 \mathrm{~h}$ light:dark conditions for at least 2 days before sleep tests. One day of sleep data were first recorded at $22^{\circ} \mathrm{C}$ as baseline, then the flies were shifted to $25.5^{\circ} \mathrm{C}, 27^{\circ} \mathrm{C}, 28.5^{\circ} \mathrm{C}$, or $30^{\circ} \mathrm{C}$ for two days, and then returned to $22^{\circ} \mathrm{C}$ for at least one day. Sleep was analyzed as previously described [7]. Changes in total sleep were calculated as the percentage of sleep change on the first day of temperature shift relative to baseline sleep at $22^{\circ} \mathrm{C}$.

\section{Courtship and Locomotion Assay}

We used unilateral wing extension in isolated males to compare courtship induced by $\mathrm{P} 1$ activation. Males were individually placed in $2 \mathrm{~cm}$-diameter round chambers with food $\left(2 \%\right.$ agarose and $5 \%$ sugar) at $25.5^{\circ} \mathrm{C}, 27^{\circ} \mathrm{C}, 28.5^{\circ} \mathrm{C}$, or $30^{\circ} \mathrm{C}$ and video was captured for $24 \mathrm{~h}$, starting at 09:00. We then manually scored the percentage of males displaying unilateral wing extension. The average walking velocity during the 24-h recording was further quantified using the ZebraLab software system (ViewPoint Life Sciences, Montreal, Quebec, Canada).

\section{Feeding}

Feeding was assayed using food with blue dye. In brief, flies were starved for $24 \mathrm{~h}$ on $1 \%$ aqueous agarose at $22^{\circ} \mathrm{C}$, then moved to $25.5^{\circ} \mathrm{C}, 27^{\circ} \mathrm{C}, 28.5^{\circ} \mathrm{C}$, or $30^{\circ} \mathrm{C}$ for $30 \mathrm{~min}$ for $d \operatorname{Trp} A 1$ activation. Thereafter, they were transferred to $1 \%$ FD\&C Blue 1 (Sigma-Aldrich, St. Louis, MO) food (2.5\% sucrose, $2.5 \%$ yeast extract, and $0.5 \%$ agar) for 15 min (between 15:00 and 17:00) at the above temperatures for continuous activation while allowing feeding. To quantify the food intake, the absorbance of the ingested blue dye was measured as previously described [24].

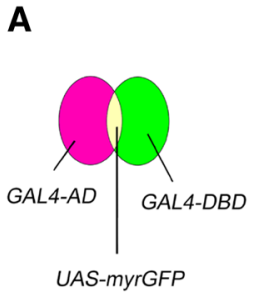

B

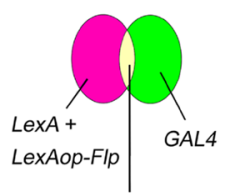

UAS>stop>myrGFP

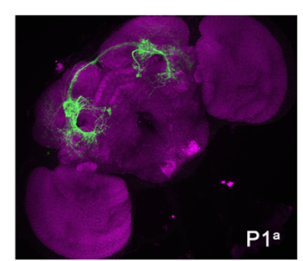

R15A01-AD; R71G01-DBD

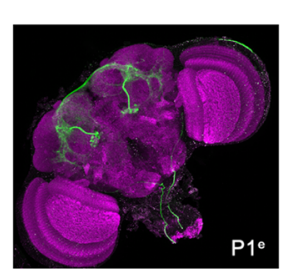

dsXGAL4 $\cap$ R71G01-LexA

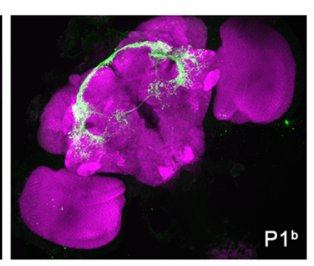

R15A01-AD; R22D03-DBD

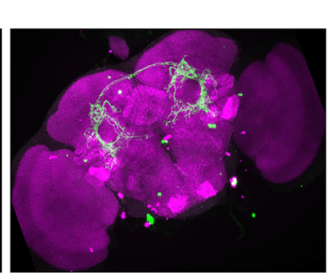

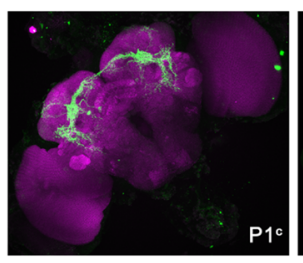

R17D06-AD; R71G01-DBD

C

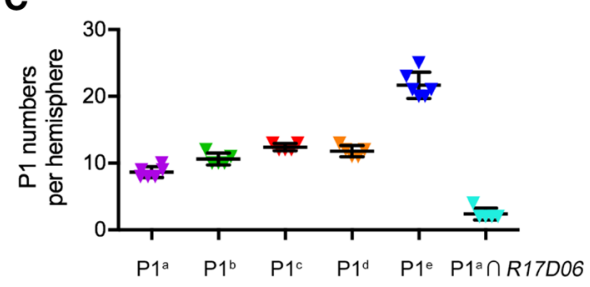

Fig. 1 Identification of drivers targeting P1 neurons in male flies. A Labeling of P1 neurons in brains of male flies by four split-GAL4 combinations ( $\mathrm{P}^{\mathrm{a}}$ by $R 15 A 01-A D ; R 71 G 01-D B D, \mathrm{P} 1^{\mathrm{b}}$ by $R 15 A 01-$ $A D ; R 22 D 03-D B D, \mathrm{P}^{\mathrm{c}}$ by $R 17 D 06-A D ; R 71 G 01-D B D$, and $\mathrm{P} 1^{\mathrm{d}}$ by $R 17 D 06-A D ; R 22 D 03-D B D)$. B Diagram of the FRT/FLP intersectional strategy to label $\mathrm{P}^{\mathrm{e}}$ neurons $($ R71G01-LexA/LexAop2-FlpL;
$U A S>$ stop $>$ myrGFP/dsx $x^{G A L 4}$ ). This method also labeled two pairs of $\mathrm{P} 1$ neurons with both $\mathrm{P} 1^{\mathrm{a}}$-splitGAL4 and R17D06-LexA. C Numbers of $\mathrm{P} 1$ neurons labeled in male flies by each of the above driver lines ( $n=6$ for $\mathrm{P}^{\mathrm{a}}$ and $\mathrm{P} 1^{\mathrm{e}}, n=5$ for the others; error bars indicate SEM). 


\section{Tissue Dissection, Staining, and Imaging}

We dissected the brains of 4-6 day-old male or female flies in Schneider's insect medium (Thermo Fisher Scientific, Waltham, MA) and fixed them in $4 \%$ paraformaldehyde in phosphate-buffered saline (PBS) for $30 \mathrm{~min}$ at room temperature. After $4 \times 15$-min washes in PAT $(0.5 \%$ Triton X-100 and $0.5 \%$ bovine serum albumin in PBS), tissues were blocked in $3 \%$ normal goat serum (NGS) for $60 \mathrm{~min}$, then incubated in primary antibodies diluted in 3\% NGS for $\sim 24 \mathrm{~h}$ at $4^{\circ} \mathrm{C}$, washed $(4 \times 15$-min) in PAT, and incubated in secondary antibodies diluted in $3 \%$ NGS for $\sim 24 \mathrm{~h}$ at $4^{\circ} \mathrm{C}$. Tissues were then washed $(4 \times 15$-min $)$ in PAT and mounted in Vectashield (Vector Laboratories, Burlingame, CA) for imaging. The primary antibodies used were rabbit anti-GFP $(1: 1000$; A11122, Invitrogen, Waltham, MA) and mouse anti-Bruchpilot (1:30; nc82, Developmental Studies Hybridoma Bank, Iowa City, IA). The secondary antibodies used were goat anti-mouse $\operatorname{IgG}$ conjugated to Alexa 555 (1:500, A28180, Invitrogen) and goat anti-rabbit $\operatorname{IgG}$ conjugated to Alexa 488 (1:500, A11008, Invitrogen). Samples were imaged at $20 \times$ magnification on a Zeiss 700 confocal microscope, and processed with ImageJ.

\section{Statistics}

Statistical analysis was performed using Prism GraphPad as indicated in the figure legends.

\section{Results and Discussion}

To investigate how P1 neurons modulate different behaviors, we first aimed to identify distinct GALA drivers for labeling and manipulating P1 neurons. We previously used two intersectional methods to target P1 neurons, one using
Fig. 2 Regulation of sleep, courtship, and feeding behaviors by P1 neurons. A-D Mild activation of $\mathrm{P} 1$ neurons driving dTrpA1 at $27^{\circ} \mathrm{C}$ using five independent $\mathrm{P} 1$ drivers $\left(\mathrm{P}^{\mathrm{a}}{ }_{-}\right.$ $\left.\mathrm{P} 1^{\mathrm{e}}\right)$ inhibited sleep (A, B), but did not affect courtship (C) or feeding (D) [sleep test at $27^{\circ} \mathrm{C}$ (A, B), $n=32$ each; wingextension test (C), $n=48$ each; feeding test (D), $n=10,10,10$, 9, 9, 10, and 10 (10 flies for each replicate)]. E-H Stronger activation of $\mathrm{P} 1$ neurons at $30^{\circ} \mathrm{C}$ using all $\mathrm{P} 1$ drivers affected sleep $(\mathbf{E}, \mathbf{F})$, while four drivers $\left(\mathrm{P} 1^{\mathrm{a}}, \mathrm{P} 1^{\mathrm{c}}, \mathrm{P} 1^{\mathrm{d}}\right.$, and $\left.\mathrm{P} 1^{\mathrm{e}}\right)$ affected courtship $(\mathbf{G})$, and only one $\left(\mathrm{P} 1^{\mathrm{e}}\right)$ affected feeding (H) [sleep test at $30^{\circ} \mathrm{C}(\mathbf{E}, \mathbf{F})$, $n=31,32,32,32,58$, and 32 ; wing-extension test (G), $n=48$ each; feeding test $(\mathbf{H}), n=10$ each]. $* * * P<0.001$, one-way ANOVA. N.S., no significant difference. Error bars indicate SEM.
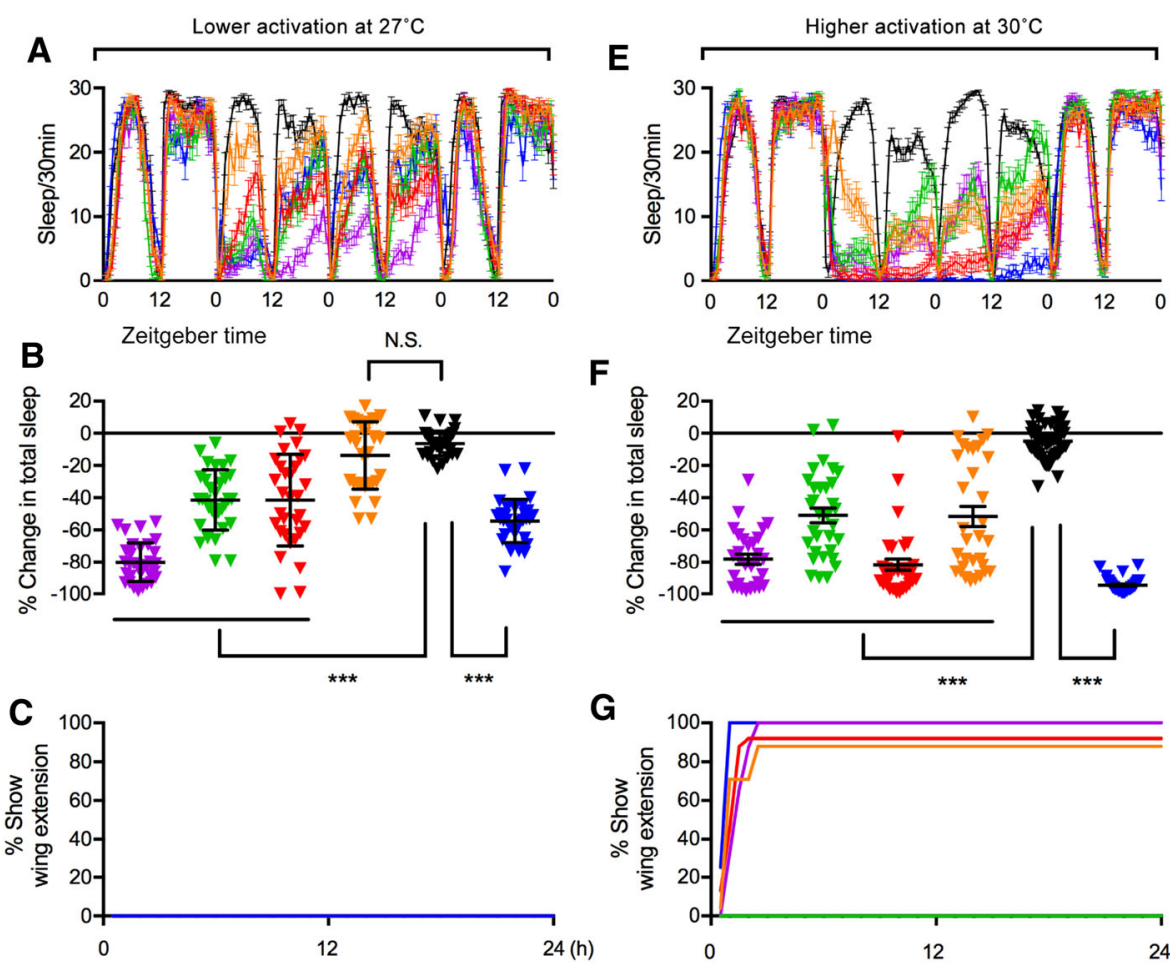

$\mathbf{F}$
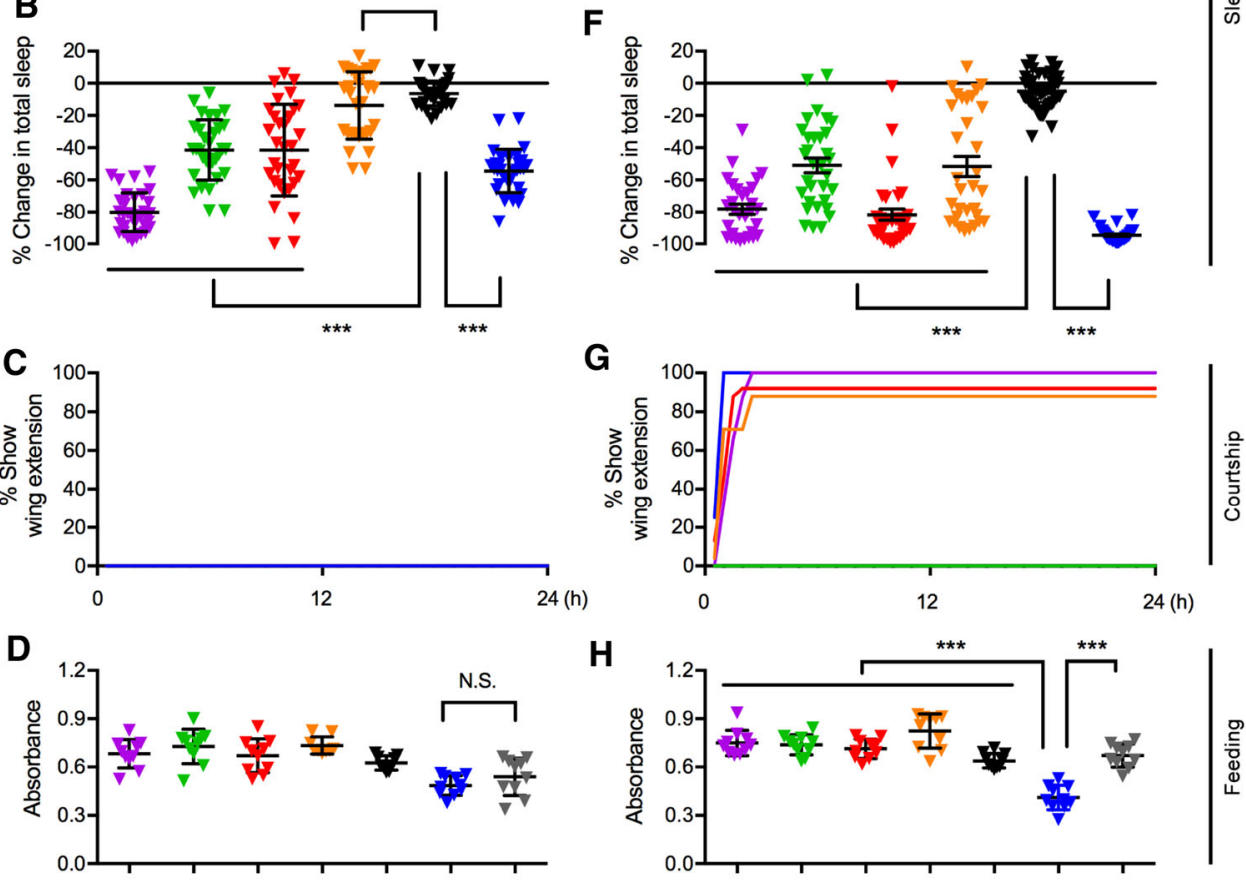

H
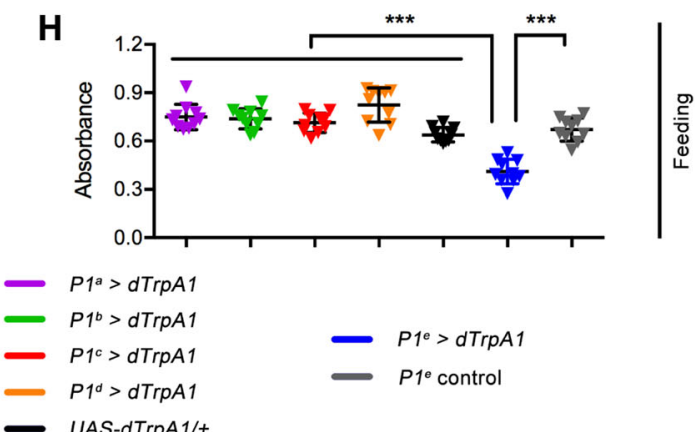
the split-GAL4 system ( $1^{\mathrm{a}}{ }^{\mathrm{a}}$-splitGAl4: R15A01-AD; R71G01-DBD, Fig. 1A), and the other using the Flip-out system (P1 ${ }^{\mathrm{e}}$ : R71G01-LexA/LexAop2-FlpL; UAS $>$ stop $>$ $m y r G F P / d s x^{G A L 4}$, Fig. 1B) [7]. We later identified two fragment GAL4s (RI7DO6 and R22D03) that also label male-specific P1 neurons and thus made three additional splitGAL4s ( $\mathrm{P} 1^{\mathrm{b}}$ by R15A01-AD; R22D03-DBD, $\mathrm{P} 1^{\mathrm{c}}$ by $R 17 D 06-A D ; \quad R 71 G 01-D B D$, and $\mathrm{P}^{\mathrm{d}}$ by R17D06-AD; R22D03-DBD). The four split-GAL4s each labeled 9-12 P1 neurons (Fig. 1C), $\sim 20 \%-25 \%$ of all P1 neurons, as well as a few other cells. Although we hoped to target distinct subsets of P1 neurons with different split-GAL4 drivers, we were not able to discriminate among them.

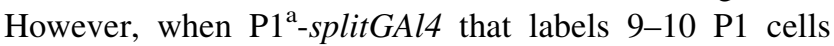
intersected with R17D06-LexA, only $\sim 2 \mathrm{P} 1$ neurons were consistently labeled, suggesting that only two P1 neurons are labeled by both drivers. Thus, it was highly likely that these four P1-splitGAL4 drivers partially overlapped as well as targeting distinct P1 neurons.

We next used these five $\mathrm{P} 1$ drivers $\left(\mathrm{P} 1^{\mathrm{a}}-\mathrm{P} 1^{\mathrm{d}}\right.$ splitGAl4s, and $\mathrm{P}^{\mathrm{e}}$ from intersection between R71G01-LexA and $d s x^{G A L 4}$, hereafter referred to simply as $\left.\mathrm{P} 1^{\mathrm{a}}-\mathrm{P} 1^{\mathrm{e}}\right)$ to investigate how the activation of these neurons via the temperature-sensitive activator dTrpA1 [25] modulates sleep, courtship, and/or feeding behaviors. It has been shown that neurons expressing $\mathrm{dTrpA} 1$ begin to fire at $26^{\circ} \mathrm{C}$, and higher temperatures further increase their activity [26]. Thus we tested the above behaviors at four temperatures $\left(25.5^{\circ} \mathrm{C}, 27^{\circ} \mathrm{C}, 28.5^{\circ} \mathrm{C}\right.$, and $\left.30^{\circ} \mathrm{C}\right)$, at which $\mathrm{P} 1$ neurons would be increasingly activated, presenting data at $27^{\circ} \mathrm{C}$ as mild activation and $30^{\circ} \mathrm{C}$ as stronger activation unless stated otherwise. We found that mild activation of $\mathrm{P} 1^{\mathrm{a}}, \mathrm{P} 1^{\mathrm{b}}, \mathrm{P} 1^{\mathrm{c}}$, and $\mathrm{P} 1^{\mathrm{e}}$, but not $\mathrm{P} 1^{\mathrm{d}}$ neurons significantly inhibited sleep (up to $80 \%$ sleep loss, Fig. 2A, B). None of these lines induced unilateral wing extension, a key step in courtship rituals (Fig. 2C), nor did they affect feeding behavior in starved males (Fig. 2D). Furthermore, stronger activation of all $\mathrm{P} 1^{\mathrm{a}}-\mathrm{P} 1^{\mathrm{e}}$ neurons at $30^{\circ} \mathrm{C}$ significantly inhibited sleep (Fig. 2E, F), and such activation of the four sets of $\mathrm{P} 1$ neurons $\left(\mathrm{P} 1^{\mathrm{a}}, \mathrm{P} 1^{\mathrm{c}}, \mathrm{P} 1^{\mathrm{d}}\right.$, and $\left.\mathrm{P} 1^{\mathrm{e}}\right)$ was able to induce unilateral wing extension (Fig. 2G). However, only stronger activation of the $\mathrm{P}^{\mathrm{e}}$ neurons at $30^{\circ} \mathrm{C}$ significantly suppressed feeding behavior (Fig. 2H). To test whether stronger activation of $\mathrm{P} 1^{\mathrm{a}}-\mathrm{P} 1^{\mathrm{d}}$ neurons at a higher temperature affected feeding, we performed the feeding experiments at $32^{\circ} \mathrm{C}$, and found the same results as those at $30^{\circ} \mathrm{C}$. Activation of $\mathrm{P} 1^{\mathrm{e}}$, but not $\mathrm{P} 1^{\mathrm{a}}-\mathrm{P} 1^{\mathrm{d}}$ neurons, suppressed feeding at $32^{\circ} \mathrm{C}$ (Fig. S1). The $\mathrm{P} 1^{\mathrm{e}}$ driver labeled $\sim 23 \mathrm{P} 1$ neurons, while the other four P1 drivers each labeled 9-12 P1 neurons. There are at least two possibilities why only activation of $\mathrm{P} 1^{\mathrm{e}}$ but not $\mathrm{P} 1^{\mathrm{a}}-\mathrm{P} 1^{\mathrm{d}}$ neurons suppressed feeding behaviors in starved males: (1) $\mathrm{P} 1^{\mathrm{e}}$
Fig. 3 Correlation between feeding behavior and walking velocity in P1-activated male flies. A-D Mean walking velocity of the indicated genotypes at $25.5^{\circ} \mathrm{C}(\mathbf{A}), 27^{\circ} \mathrm{C}(\mathbf{B})$, $28.5^{\circ} \mathrm{C}(\mathbf{C})$, and $30^{\circ} \mathrm{C}(\mathbf{D})(n=$ 24 each, except that $n=21$ for $\mathrm{P} 1^{\mathrm{e}}$ activation at $30^{\circ} \mathrm{C}$. Error bars indicate SEM). E A slightly positive correlation between feeding and walking velocity ( $r=0.37, P=0.0503$, Pearson's correlation coefficient), so decreased feeding by $\mathrm{P} 1^{\mathrm{e}}$ activation is not due to increased locomotion.
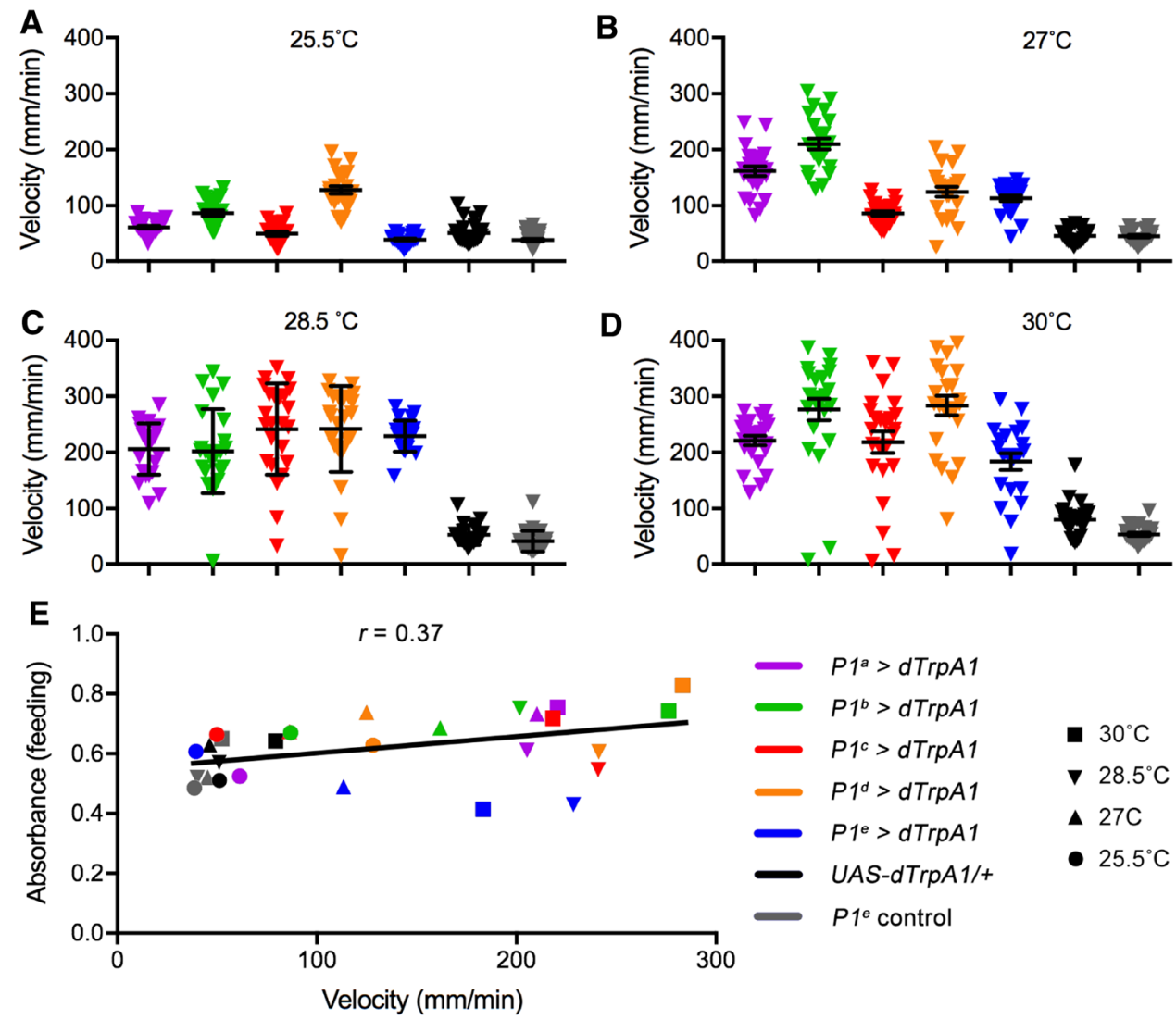
neurons include a set of neurons that are not labeled by other P1 drivers, and these neurons specifically affect feeding behavior; or (2) as the number of P1 neurons labeled by $\mathrm{P}^{\mathrm{e}}$ is about double that of $\mathrm{P}^{\mathrm{a}}-\mathrm{P} 1^{\mathrm{d}}$, it is possible that feeding requires the activation of a larger number of P1 neurons than sleep or courtship. Together, these results indicate that sleep, courtship, and feeding behaviors are all affected by activation of P1 neurons, but with different activation thresholds.

We next asked whether the suppression of feeding by activation of $\mathrm{P}^{\mathrm{e}}$ neurons was correlated with locomotor activity, as stronger activation of $\mathrm{P}^{\mathrm{e}}$ neurons at $30^{\circ} \mathrm{C}$ indeed increases walking velocity [7]. We assayed walking velocity in all $\mathrm{P} 1^{\mathrm{a}}-\mathrm{P} 1^{\mathrm{e}}$-activated males at various temperatures $\left(25.5-30^{\circ} \mathrm{C}\right.$, Fig. 3A-D) for $24 \mathrm{~h}$, and found that mild activation at $27^{\circ} \mathrm{C}$ already increased the average velocity in $\mathrm{P}^{\mathrm{e}}$-activated males, as well as in the other P1activated males. Stronger activation at $30^{\circ} \mathrm{C}$ further increased the velocity, but that of $\mathrm{P}^{\mathrm{e}}{ }^{\mathrm{e}}$-activated males was not as high as the other P1-activated males (average velocity of $\mathrm{P}^{\mathrm{a}}-\mathrm{P} 1^{\mathrm{e}}$-activated males: $221.0 \pm 8.4,266.6 \pm$ $19.1,218.6 \pm 19.3,283.5 \pm 17.3$, and $183.7 \pm 15.0 \mathrm{~mm} /$ min, respectively). The two control lines also showed a slightly increased walking velocity at $30^{\circ} \mathrm{C}$. As only activation of $\mathrm{P} 1^{\mathrm{e}}$ neurons, but not $\mathrm{P} 1^{\mathrm{a}}-\mathrm{P} 1^{\mathrm{d}}$, suppressed feeding, this suppression could not be due to increased locomotion. To further test if feeding and walking velocity were negatively correlated, we plotted all the feeding and locomotor data for all P1-activated males and control males at $25.5^{\circ} \mathrm{C}, 27^{\circ} \mathrm{C}, 28.5^{\circ} \mathrm{C}$, and $30^{\circ} \mathrm{C}$, and found that feeding and walking velocity were not negatively correlated, and even slightly positively correlated $(r=0.37)$, although the correlation was not significant $(P=0.0503)$. These results indicate that decreased feeding by $\mathrm{P} 1^{\mathrm{e}}$ activation is not due to increased locomotion. How $\mathrm{P} 1^{\mathrm{e}}$ neurons regulate feeding is still unclear and awaits further investigation.

In summary, we used five independent P1 drivers that potentially labeled partially overlapping and distinct P1 neurons, and systematically investigated how different activation levels $\left(25.5^{\circ} \mathrm{C}, 27^{\circ} \mathrm{C}, 28.5^{\circ} \mathrm{C}\right.$, and $\left.30^{\circ} \mathrm{C}\right)$ of these targeted P1 neurons affect sleep, courtship, and feeding behaviors. We found that all these behaviors were affected by stronger activation of at least one $\mathrm{P} 1$ driver (e.g., $\mathrm{P} 1^{\mathrm{e}}$ ), suggesting that P1 activity affects all sleep, courtship, and feeding behaviors. Furthermore, we found that differential activation thresholds for P1 neurons were required to affect these three behaviors (Fig. 4A). First, minimum activation (mild activation of 9-12 P1 neurons) was sufficient to suppress sleep; second, stronger activation of P1 neurons was required to induce courtship behavior; and third, only stronger activation of $\mathrm{P} 1^{\mathrm{e}}$ that included $\sim 23 \mathrm{P} 1$ neurons affected feeding.

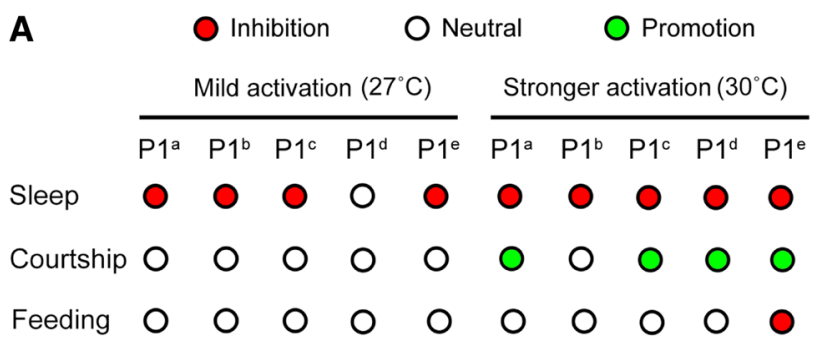

B

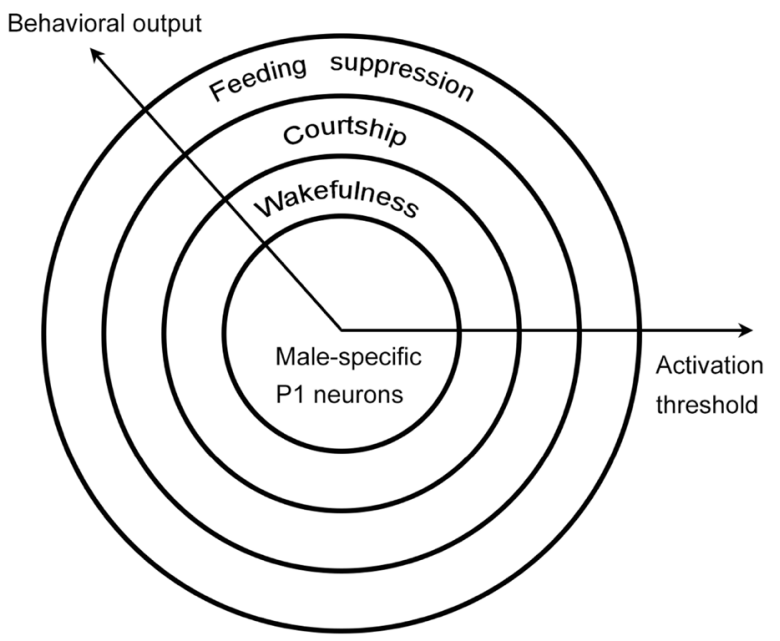

Fig. 4 Hierarchical control of sleep, courtship, and feeding by P1 neurons. A Summary of the effects of mild and strong activation of P1 neurons using five independent drivers $\left(\mathrm{P} 1^{\mathrm{a}}-\mathrm{P} 1^{\mathrm{e}}\right)$ on sleep, courtship, and feeding behaviors in male flies. B Proposed hierarchical model in which different activation thresholds (e.g., activation levels, number of neurons) are required for P1 neurons to modulate sleep/wakefulness, courtship, and feeding behaviors.

Sleep, courtship, and feeding are competing behaviors that are mediated by external sensory cues and internal states. Whether these competing behaviors are regulated by common neural nodes is an intriguing question. P1 neurons have been established as a center that mediates sexual arousal, but their role in regulating other internal states and behaviors has been underestimated. Our findings that P1 neurons mediate sleep, courtship, and feeding behaviors not only reveal a neural node (P1) that participates in all these competing behaviors, but also how P1 neurons modulate these behaviors in a hierarchical manner (Fig. 4B).

There are nearly 50 pairs of $\mathrm{P} 1$ neurons in the male fly brain [27], and we studied here only $20 \%-50 \%$ of them. Given that mild activation of $\sim 10 \mathrm{P} 1$ neurons was sufficient to inhibit sleep, and stronger activation of $\sim 23$ (nearly half) suppressed feeding, what if the other half or all P1 neurons were activated? Do P1 neurons regulate behaviors other than sleep, courtship, aggression, and feeding? Is P1 a center for internal states that coordinate different behaviors? To answer these questions, better tools 
are needed to subdivide P1 populations, with driver lines that target small and distinct subsets of P1 neurons and driver lines targeting all or the majority of P1 neurons.

We also note that, although males and females play distinct roles in sexual behavior, their differences in nonsexual behaviors (e.g., different amounts of sleep or feeding) are relatively smaller and underestimated, and the mechanism underlying these differences is unclear. That P1 neurons are male-specific and regulate sleep, courtship, aggression, and feeding suggests that sexual dimorphism in these behaviors may be greater than we thought, and our results provide a simple model of how a small number of sex-specific neurons can contribute to various sexually-dimorphic behaviors.

Acknowledgements We thank the Rubin lab at Janelia Research Campus for the fly stocks. This work was supported by the Natural Science Foundation of Jiangsu Province of China (BK20150597 and BK20160025), the National Natural Science Foundation of China (31571093 and 31622028), and the Thousand Young Talents Program in China.

Open Access This article is distributed under the terms of the Creative Commons Attribution 4.0 International License (http:// creativecommons.org/licenses/by/4.0/), which permits unrestricted use, distribution, and reproduction in any medium, provided you give appropriate credit to the original author(s) and the source, provide a link to the Creative Commons license, and indicate if changes were made.

\section{References}

1. Bushey D, Cirelli C. From genetics to structure to function: exploring sleep in Drosophila. Int Rev Neurobiol 2011, 99: 213-244.

2. Flood TF, Iguchi S, Gorczyca M, White B, Ito K, Yoshihara M. A single pair of interneurons commands the Drosophila feeding motor program. Nature 2013, 499: 83-87.

3. Harbison ST, Mackay TF, Anholt RR. Understanding the neurogenetics of sleep: progress from Drosophila. Trends Genet 2009, 25: 262-269.

4. Manoli DS, Foss M, Villella A, Taylor BJ, Hall JC, Baker BS. Male-specific fruitless specifies the neural substrates of Drosophila courtship behaviour. Nature 2005, 436: 395-400.

5. Pool AH, Scott K. Feeding regulation in Drosophila. Curr Opin Neurobiol 2014, 29C: 57-63.

6. Stockinger P, Kvitsiani D, Rotkopf S, Tirian L, Dickson BJ. Neural circuitry that governs Drosophila male courtship behavior. Cell 2005, 121: 795-807.

7. Chen D, Sitaraman D, Chen N, Jin X, Han C, Chen J, et al. Genetic and neuronal mechanisms governing the sex-specific interaction between sleep and sexual behaviors in Drosophila. Nat Commun 2017, 8: 154.

8. Clowney EJ, Iguchi S, Bussell JJ, Scheer E, Ruta V. Multimodal chemosensory circuits controlling male courtship in Drosophila. Neuron 2015, 87: 1036-1049.
9. Inagaki HK, Jung Y, Hoopfer ED, Wong AM, Mishra N, Lin JY, et al. Optogenetic control of Drosophila using a red-shifted channelrhodopsin reveals experience-dependent influences on courtship. Nat Methods 2014, 11: 325-332.

10. Kallman BR, Kim H, Scott K. Excitation and inhibition onto central courtship neurons biases Drosophila mate choice. Elife 2015, 4: e11188.

11. Kohatsu S, Koganezawa M, Yamamoto D. Female contact activates male-specific interneurons that trigger stereotypic courtship behavior in Drosophila. Neuron 2011, 69: 498-508.

12. Zhang SX, Rogulja D, Crickmore MA. Dopaminergic circuitry underlying mating drive. Neuron 2016, 91: 168-181.

13. Hoopfer ED, Jung Y, Inagaki HK, Rubin GM, Anderson DJ. P1 interneurons promote a persistent internal state that enhances inter-male aggression in Drosophila. Elife 2015, 4.

14. Kimura K, Hachiya T, Koganezawa M, Tazawa T, Yamamoto D. Fruitless and doublesex coordinate to generate male-specific neurons that can initiate courtship. Neuron 2008, 59: 759-769.

15. Pan Y, Meissner GW, Baker BS. Joint control of Drosophila male courtship behavior by motion cues and activation of male-specific P1 neurons. Proc Natl Acad Sci U S A 2012, 109: 10065-10070.

16. von Philipsborn AC, Liu T, Yu JY, Masser C, Bidaye SS, Dickson BJ. Neuronal control of Drosophila courtship song. Neuron 2011, 69: 509-522.

17. Burtis KC, Baker BS. Drosophila doublesex gene controls somatic sexual differentiation by producing alternatively spliced mRNAs encoding related sex-specific polypeptides. Cell 1989, 56: 997-1010.

18. Demir E, Dickson BJ. fruitless splicing specifies male courtship behavior in Drosophila. Cell 2005, 121: 785-794.

19. Pan Y, Baker BS. Genetic identification and separation of innate and experience-dependent courtship behaviors in Drosophila. Cell 2014, 156: 236-248.

20. Ryner LC, Goodwin SF, Castrillon DH, Anand A, Villella A, Baker BS, et al. Control of male sexual behavior and sexual orientation in Drosophila by the fruitless gene. Cell 1996, 87: 1079-1089.

21. Pfeiffer BD, Jenett A, Hammonds AS, Ngo TT, Misra S, Murphy $\mathrm{C}$, et al. Tools for neuroanatomy and neurogenetics in Drosophila. Proc Natl Acad Sci U S A 2008, 105: 9715-9720.

22. Pfeiffer BD, Ngo TT, Hibbard KL, Murphy C, Jenett A, Truman JW, et al. Refinement of tools for targeted gene expression in Drosophila. Genetics 2010, 186: 735-755.

23. Pan Y, Robinett CC, Baker BS. Turning males on: activation of male courtship behavior in Drosophila melanogaster. PLoS One 2011, 6: e21144.

24. Deshpande SA, Carvalho GB, Amador A, Phillips AM, Hoxha S, Lizotte KJ, et al. Quantifying Drosophila food intake: comparative analysis of current methodology. Nat Methods 2014, 11: 535-540.

25. Hamada FN, Rosenzweig M, Kang K, Pulver SR, Ghezzi A, Jegla $\mathrm{TJ}$, et al. An internal thermal sensor controlling temperature preference in Drosophila. Nature 2008, 454: 217-220.

26. Pulver SR, Pashkovski SL, Hornstein NJ, Garrity PA, Griffith LC. Temporal dynamics of neuronal activation by Channelrhodopsin-2 and TRPA1 determine behavioral output in Drosophila larvae. J Neurophysiol 2009, 101: 3075-3088.

27. Cachero S, Ostrovsky AD, Yu JY, Dickson BJ, Jefferis GS. Sexual dimorphism in the fly brain. Curr Biol 2010, 20: 1589-1601. 